STRUCTURAL BIOLOGY

ISSN 2059-7983

\section{Protein Tyrosine Phosphatases. Structure, Signaling and Drug Discovery. Edited by L. G. Ahuja. De Gruyter, 2018. Pp. 282. Price (hardback) 139.95 EUR, 160.99 USD, 127 GBP. ISBN 978-3-11-042643-4.}

\author{
Jean-Pierre Jacquot*
}

Université de Lorraine, INRA, Laboratoire Interaction Arbres Microorganismes, Nancy, France. *Correspondence e-mail: j2p@univ-lorraine.fr

Protein Tyrosine Phosphatases is a book of $\sim 280$ pages written by Dr Lalima G. Ahuja, who is currently a postdoctoral student at the University of California San Diego in the Department of Pharmacology. Her training is in molecular biophysics and thus she is very well suited for the task. Following a short introductory preface, the book is divided into eight different chapters.

The first chapter is mostly historical but also contains more recent data. It recollects the discovery of protein phosphorylation and especially of tyrosine phosphorylation. It describes tyrosine kinases, their structures and their mode of regulation, and then turns its attention to the phosphotyrosine recognition domains in the $\mathrm{SH} 2$ and PTB domain containing proteins.

The second chapter deals with the classification of protein phosphatases. The author first indicates that there are several types of protein phosphatases which are categorized depending on the nature of the phosphorylated amino acid (either Ser or Thr, or Tyr). Overall there are 15 families of protein phosphatases, 3 of them acting as Ser/Thr phosphatases and the rest as Tyr phosphatases. Amazingly enough, there are more than 100 genes coding for the various protein tyrosine phosphatases (PTPs) in the human genome. This chapter then sets out to describe the relative properties of protein phosphatases especially at the structural level, detailing in particular the fold of the 12 classes of PTPs and the nature of the protein modules that constitute them. The mechanisms of Cys- and Asp-based catalysis are also briefly addressed. There is actually some redundancy between this more general chapter and the next five chapters, especially Chapter 3 which details the three-dimensional organization of the various domains. In this chapter a very useful table (Table 3.1) provides a summary of all the PTP proteins of the human genome (two pages are required) and two additional tables detail conserved sequences that have helped classify the various families.

Chapter 4 is dedicated to the structure and function of receptor PTPs, and their modular organization and structures are detailed at length. This chapter also addresses their physiological function in signal transduction. Chapter 5 also deals with receptor protein tyrosine phosphatases but focuses on those possessing double domains. Interestingly, it addresses the question of their regulation via the reversible oxidation of cysteine residues. Chapters 6 and 7 detail the non-receptor protein tyrosine phosphatases and not only address their structures, physiological functions and regulation but also their role in cancer and as therapeutic targets. Finally Chapter 8 evaluates the strategies for drug development linked to the PTPs.

Overall, after giving a presentation of the field including the necessity for amino acid phosphorylation and dephosphorylation, the book details the organization of the very large families of PTPs - which is not an easy task. I believe that the author has succeeded reasonably well given the complexity of the PTP families. This is actually an amazing task for a postdoctoral student and it certainly reveals high scientific maturity. The literature cited is abundant with overall more than 1000 citations in the book. On the negative side there is some redundancy between the chapters and there are a number of typographical errors, and the quality of the figures (especially of the structures) is not very high, which is unfortunate. It should be mentioned that this book essentially addresses the significance 


\section{book reviews}

of phosphotyrosine dephosphorylation in animal/mammalian systems and to some extent in bacteria. The plant world is completely ignored even though PTPs are present (Luan, 2003) and share homology with the animal counterparts in comparison with the tyrosine kinases which apparently remain elusive in the green lineage. Despite these moderate draw- backs, I believe one should congratulate the author for such a remarkable bibliographic achievement.

\section{References}

Luan, S. (2003). Annu. Rev. Plant Biol. 54, 63-92. 